\title{
The Effect of Isothermal Multi-Directional Forging on the Grain Structure, Superplasticity, and Mechanical Properties of the Conventional Al-Mg-Based Alloy
}

\author{
Anastasia V. Mikhaylovskaya *, Anton D. Kotov@ ${ }^{\circledR}$, Mikhail S. Kishchik, Alexey S. Prosviryakov \\ and Vladimir K. Portnoy \\ Department of Physical Metallurgy of Non-Ferrous Metals, National University of Science and Technology \\ “MISiS", Leninsky Prospekt 4, 119049 Moscow, Russia; kotov@misis.ru (A.D.K.); tanais61@bk.ru (M.S.K.); \\ pro.alex@mail.ru (A.S.P.); portnoy@misis.ru (V.K.P.) \\ * Correspondence: mihaylovskaya@misis.ru; Tel.: +7-495-683-4480
}

Received: 7 December 2018; Accepted: 27 December 2018; Published: 2 January 2019

\begin{abstract}
The current study observed a grain structure evolution in the central part and periphery of the sample of an Al-Mg-Mn-based alloy during isothermal multidirectional forging (IMF) at $350{ }^{\circ} \mathrm{C}$ with a cumulative strain of 2.1-6.3 and a strain per pass of 0.7. A bimodal grain size distribution with areas of fine and coarse grains was observed after IMF and subsequent annealing. The grain structure, mechanical properties, and superplastic behavior of the samples subjected to IMF with a cumulative strain of 6.3 and the samples exposed to IMF with subsequent cold rolling were compared to the samples exposed to a simple thermo-mechanical treatment. The micro-shear bands were formed inside original grains after the first three passes. The fraction of recrystallized grains increased and the mean size decreased with an increasing cumulative strain from 2.1 to 6.3. Significant improvements of mechanical properties and superplasticity were observed due to the formation of a homogenous fine grain structure $4.8 \mu \mathrm{m}$ in size after treatment including IMF and subsequent cold rolling.
\end{abstract}

Keywords: aluminum alloy; isothermal multi-directional forging; grain refinement; microstructure evolution; mechanical properties; superplasticity

\section{Introduction}

The effects of severe plastic deformation (SPD) to the microstructure and properties of aluminum alloys have hardly been studied during the last decade. Many SPD methods have been analyzed, and their advantages and disadvantages are known [1-6]. Grain fragmentation and continuous dynamic/post-dynamic recrystallization $[7,8]$ occur at SPD and provide an ultra-fine grain structure consisting of grains with high angle grain boundary misorientation $[1,2,4,6-9]$. As a result, ultra-fine grain aluminum alloys exhibit increased mechanical properties at room temperature $[1,4,7,10]$ and superplasticity at elevated temperatures [11-15]. The main disadvantage of the SPD technique is an increase in the cost of semi-finished products, which can be critical for many applications of aluminum-based alloys. Cost inefficiency delays the industrial application of many SPD methods. Under this point of view, the most cheap, simplest, and promising SPD technique is multi-directional, or multi-axial forging $[16,17]$. This method provides significant grain refinement in various aluminum-based alloys and decreases the mean grain size to $\sim 0.5-1 \mu \mathrm{m}$ [18-20]. The main multi-directional forging (MDF) problem is a strain inhomogeneity. As a result, an inhomogeneous grain structure forms in bulk material [21-24]. The grain structure consists of very fine grains and coarse grains in pure Al subjected to multi-directional forging at room temperature $[25,26]$. Similar grain bimodalities are observed in many aluminum-based alloys [9,21,27-31]. The final grain structure and its homogeneity are 
significantly affected by the deformation temperature, cumulative strain and alloy composition [2,7-10,20]. Montazeri-Pour et al. [25] concluded that a high imposed strain per pass by more shear planes with different orientations results in more homogeneous grain fragmentation. Wang et al. [32] found that grains were uniformly distributed after MDF at $350{ }^{\circ} \mathrm{C}$ with a cumulative strain of 3.6 in an Al-Cu-based alloy, due to the grain structure being stabilized by fine precipitates. Sidtikov et al. [20] observed grain structure homogeneity with a grain size of $1.2 \mu \mathrm{m}$ after multi-directional forging under isothermal conditions (IMF) at $325{ }^{\circ} \mathrm{C}$ and cumulative strain of 8.3 in an $\mathrm{Al}-\mathrm{Mg}-\mathrm{Sc}-\mathrm{Zr}$ alloy containing the fine precipitates of the $\mathrm{Al}_{3}(\mathrm{Sc}, \mathrm{Zr})$ phase.

The effect of MDF on the room temperature mechanical properties has been widely studied [19,21,33]. It was found that the strength can be increased by several times [19] mostly due to grain boundary strengthening and the Hall-Petch relationship [1-5,19,25]. The MDF-processed ultra-fine grain structure promises a decreased temperature and an increased strain rate of superplasticity for conventional aluminum-based alloys. Meanwhile, only several documents [34,35] have reported the superplastic deformation behavior of aluminum-based alloys subjected to multi-directional forging. Noda et al. [34] found low-temperature superplasticity in AA5083 type alloys subjected to MDF at $270{ }^{\circ} \mathrm{C}$ with cumulative strain of 6 . The mean grain sizes were 0.8 and $10 \mu \mathrm{m}$ in the samples annealed at 200 and $400{ }^{\circ} \mathrm{C}$, respectively. Approximately $350 \%$ of elongation was achieved at $200{ }^{\circ} \mathrm{C}$ and $2.8 \times 10^{-4} \mathrm{~s}^{-1}$, and the elongation exceeded $400 \%$ at $400{ }^{\circ} \mathrm{C}$ at the same strain rate. Alloy exhibited high strain rate superplasticity with an $m$-value of 0.39 and an elongation to failure of $\sim 270 \%$ at a strain rate of $2.8 \times 10^{-2} \mathrm{~s}^{-1}$ and a temperature of $400^{\circ} \mathrm{C}$. Many studies have confirmed the effectiveness of MDF to improve of the superplastic properties of $\mathrm{Mg}$-based alloys [36-40]. There are insufficient data on the influence of MDF on the superplastic characteristics of other aluminum-based alloys exposed to MDF or MDF with subsequent rolling. This investigation focuses on the effect of IMF, with a large strain per pass of 0.7 , on the grain structure evolution, the superplastic deformation behavior and the room temperature mechanical properties of an Al-Mg-Mn alloy (AA5000 type) subjected to IMF alone and to IMF with subsequent cold rolling. The samples of the same alloy exposed to a simple thermo-mechanical treatment, which included hot and cold rolling, were used as a reference.

\section{Materials and Methods}

A non-heat treatable conventional Al-Mg-based alloy [41] was studied in the present research. The alloy chemical composition is shown in Table 1.

Table 1. Chemical composition of the studied alloy (wt. \%).

\begin{tabular}{ccccccccc}
\hline Element & $\mathbf{M g}$ & $\mathbf{M n}$ & $\mathbf{Z n}$ & $\mathbf{Z r}$ & $\mathbf{C r}$ & $\mathrm{Ti}$ & $\mathbf{F e}+\mathrm{Si}$ & $\mathrm{Al}$ \\
\hline Concentration & 5.66 & 0.81 & 0.67 & 0.09 & 0.07 & 0.04 & 0.3 & Base \\
\hline
\end{tabular}

An ingot with a size of $250 \times 120 \times 30 \mathrm{~mm}^{3}$ was cast using the semi-continuous casting method. Pure aluminum of $99.70 \%$, pure magnesium of $99.95 \%$, and pure zinc of $99.95 \%$, along with master alloys Al-10\% Mn, Al-4.3\% Zr, Al-10\% Cr, and Al-3.5\% Ti were used for alloy preparation. All concentrations are given in wt.\%. Melting was performed in a graphite-fireclay crucible using a laboratory electric resistance furnace (Naberterm S3, Nabertherm GmbH, Lilienthal, Germany). The temperature before casting was $740{ }^{\circ} \mathrm{C}$. The casting cooling rate was $\sim 3 \mathrm{~K} / \mathrm{min}$.

The grain structure, superplastic deformation behavior, and mechanical properties of the samples subjected to different thermo-mechanical treatments were compared. The sample after IMF (mode A), the sample subjected to IMF and cold rolling (mode B) and the sample subjected to hot rolling and cold rolling (mode C) were studied. The steps of the applied treatment modes are shown in Figure 1. 


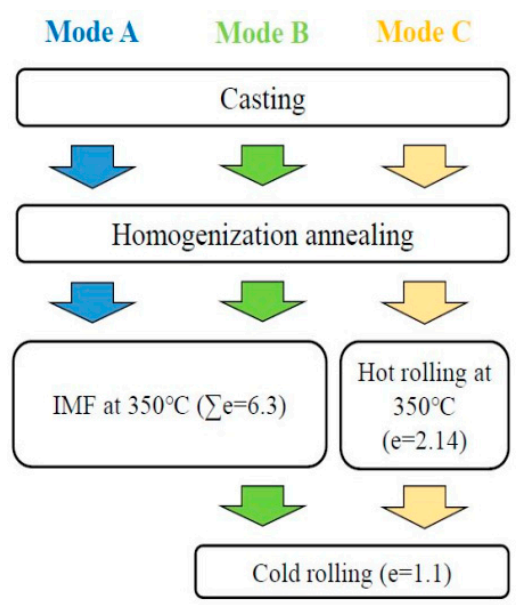

Figure 1. The thermo-mechanical treatment regimes (modes A, B and C).

Heat treatment was conducted in a Nabertherm N30/65A (Nabertherm GmbH, Lilienthal, Germany) furnace with an air atmosphere. Homogenization annealing was carried out in two stages at $430{ }^{\circ} \mathrm{C}$ for $5 \mathrm{~h}$ and at $480^{\circ} \mathrm{C}$ for $3 \mathrm{~h}$.

The isothermal multi-directional forging (IMF) was performed in a hydraulic press machine (Nordberg N3650E, Changshu Tongrun Auto Acessory Co., LTD, Changshu, China) with a maximum load of 50 tons. The scheme of the IMF deformation process is shown in Figure 2. The special dye was used to maintain a constant size in a one direction during forging. A constant sample geometry with an aspect ratio of $1 \times 1 \times 2 \mathrm{~mm}^{3}$ was provided after each IMF pass. The sample size was $56 \times 28 \times 28 \mathrm{~mm}^{3}$. IMF was performed at a temperature of $350{ }^{\circ} \mathrm{C}$ and an initial strain rate of $6 \times 10^{-3} \mathrm{~s}^{-1}$. The samples were maintained at $350{ }^{\circ} \mathrm{C}$ for $20 \mathrm{~min}$ before starting each compression. A strain of 0.7 per pass and a cumulative strain of $\sum \mathrm{e}=2.1$ per cycle were applied [42]. A graphite-based lubricant (Liqui Moly, Ulm, Germany) was used to decrease the friction between the die elements and the sample.

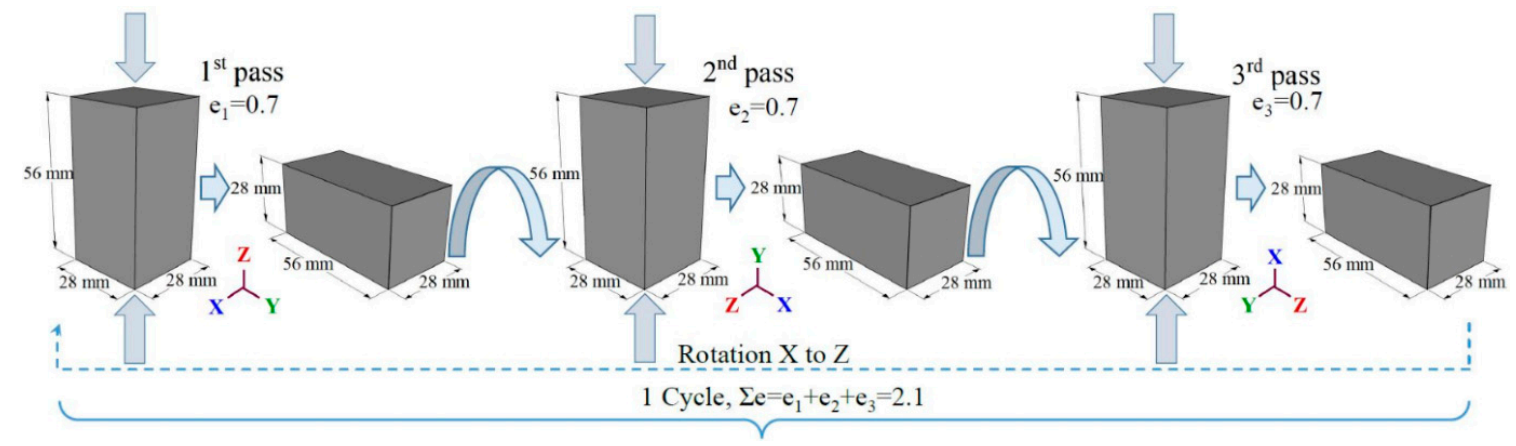

Figure 2. The scheme of sample rotation during isothermal multidirectional forging.

Hot and cold rolling were carried out on a laboratory rolling mill V-3P (GMT, Saint-Petersburg, Russia) with a roll diameter of $200 \mathrm{~mm}$. The hot rolling reduction was $2.14(88 \%)$ and the cold rolling reduction was $1.1(67 \%)$.

An Axiovert 200 MMAT (Carl Zeiss, Oberkochen, Germany) optical light microscope (LM) in a polarized light regime was used for the grain structure analysis. Specimens for microstructure study were prepared by mechanical grinding on $\mathrm{SiC}$ papers and polishing on a colloidal silica suspension using a Struers LaboPol-5 (Struers APS, Ballerup, Denmark) machine. Subsequent anode oxidizing was performed in a Baker solution at $20 \mathrm{~V}$. The grain structure was controlled after various IMF passes and thermo-mechanical treatment including IMF and hot and cold rolling. The microstructures of the IMF processed samples were analyzed in the near-surface layer (see Figure 2, Z-X plane after the first pass, Y-Z after the second pass and X-Y plane after the third pass) to study a grain structure in the 
periphery of the samples. The middle cross section ( $Z / 2, X-Y$ plane in Figure 2 after the third pass) was analyzed to study the grain structure in the central part of the samples.

Tensile tests were performed at elevated temperatures of 500 and $540^{\circ} \mathrm{C}$ on a Walter + Bay LFM100 test machine (Walter + Bai AG, Löhningen, Switzerland). Two test types were used: (1) step-by-step increase of the strain rate in a range of $8 \times 10^{-5}$ to $1 \times 10^{-1} \mathrm{~s}^{-1}$ and (2) constant strain rate tests at $1 \times 10^{-3}, 5 \times 10^{-3}$ and $1 \times 10^{-2} \mathrm{~s}^{-1}$. The samples had a gauge size of $F_{0}=6 \times 1 \mathrm{~mm}^{2}$ and a length of $l_{0}=14 \mathrm{~mm}\left(l_{0}=5.65 \sqrt{F_{0}}\right)$.

The mechanical properties at room temperature were analyzed using a uniaxial tensile test on a Zwick Z250 (Zwick Roell Group, Ulm, Germany) test machine. A yield strength (YS), an ultimate tensile strength (UTS) and an elongation to failure were determined. The "dog bone" type samples had a gauge size of $F_{0}=3 \times 1 \mathrm{~mm}^{2}$ and a length of $L_{0}=10 \mathrm{~mm}$ (according to the ISO 6892-1 standard). The tensile tests were performed at traverse rate of $4 \mathrm{~mm} / \mathrm{min}$. Three samples per state were studied for room and elevated temperature tests.

Melting, heat and deformation treatments, and mechanical tests were performed in air atmosphere. The liner intercept method was used to determine a mean grain size. Three samples were studied for each state. The areas of coarse and fine grains were measured separately. The error bars were calculated as $E=S \times t / \sqrt{N}$, were $S$ is a standard deviation, $t$ is a Student coefficient for confidence probability 0.95 , and $N$ is an amount of measurements $(N \approx 100$ for coarse grained areas and $N$ varied in a range of $300-500$ for fine grained areas.

\section{Results and Discussion}

\subsection{Grain Structure Evolution at IMF}

The initial grain structure after homogenization annealing was equiaxed with a mean grain size of $143 \pm 20 \mu \mathrm{m}$ (Figure 3a). The grain structure evolution after IMF at $350{ }^{\circ} \mathrm{C}$ in the near-surface layer is shown at Figure $3 \mathrm{~b}-\mathrm{f}$. The first IMF pass with a strain of 0.7 made the grains slightly elongated (Figure $3 b$ ), and the grain structure was transformed to the banded structure during the second and third IMF passes (Figure 3). The micro-shear bands (MSBs) $[7,20]$ formed after the second IMF pass and their density increased after the third pass due an increase in the cumulative strain to 2.1. There was no recrystallization effect on the periphery of the sample at a cumulative strain of 2.1 (one cycle). An increase in the cumulative strain to 4.2 (two cycles) provided the dynamic/post-dynamic recrystallization $[7,43]$. New equiaxed grains formed on the initial grain boundaries in the near-surface layer. The fraction of new recrystallized grains increased from 20 to $43 \%$, and the grain size slightly decreased from $3.5 \pm 0.1$ to $2.9 \pm 0.1 \mu \mathrm{m}$, with an increase in the cumulative strain from 4.2 to 6.3 . The grain structure on the periphery of the samples remained non-uniform at $\sum \mathrm{e}=6.3$.

The microstructure of the central section of the samples was studied after cumulative strains of 2.1 (one cycle), 4.2 (two cycles), and 6.3 (three cycles) (Figure 4). The fine recrystallized grains were formed only on the initial grain boundaries at $\sum \mathrm{e}=2.1$ (Figure 4a). A recrystallized fraction occupied the larger areas at cumulative strains of 4.2 and 6.3 (Figure $4 \mathrm{~b}, \mathrm{c}$ ). The volume fraction of recrystallized grains increased to $31 \%$ at $\sum \mathrm{e}=4.2$ and to $57 \%$ at $\sum \mathrm{e}=6.3$. As a result, a bimodal grain size distribution was observed in the central cross-section after IMF at $350{ }^{\circ} \mathrm{C}$ and $\sum \mathrm{e}=6.3$. Similar grain bimodality was observed after multi-directional forging of various aluminum alloys [9,27-31] and after IMF with a lower strain per pass of 0.4 and a cumulative strain of $\sum \mathrm{e}=6.1$ in the studied $\mathrm{Al}-\mathrm{Mg}-\mathrm{Mn}$ alloy [43].

The mean size of the new recrystallized grains insignificantly changed with an increase in the cumulative strain. The mean grain size in the recrystallized area decreased from $1.6 \pm 0.1 \mu \mathrm{m}$ at $\sum \mathrm{e}=2.1$ to $1.2 \pm 0.1 \mu \mathrm{m}$ at $\sum \mathrm{e}=6.3$ in the central section. It is notable that grains in the central section were 2.2-2.4 times finer than those in the periphery of the sample.

In comparison, the grain structure of the sample hot-rolled at $350{ }^{\circ} \mathrm{C}(\mathrm{e}=2.14)$ consisted of non-recrystallized elongated grains and several non-equiaxed recrystallized grains. The liner size of 
the non-equiaxed recrystallized grains in the rolling direction varied within a range of 11 to $138 \mu \mathrm{m}$ (Figure 4d).
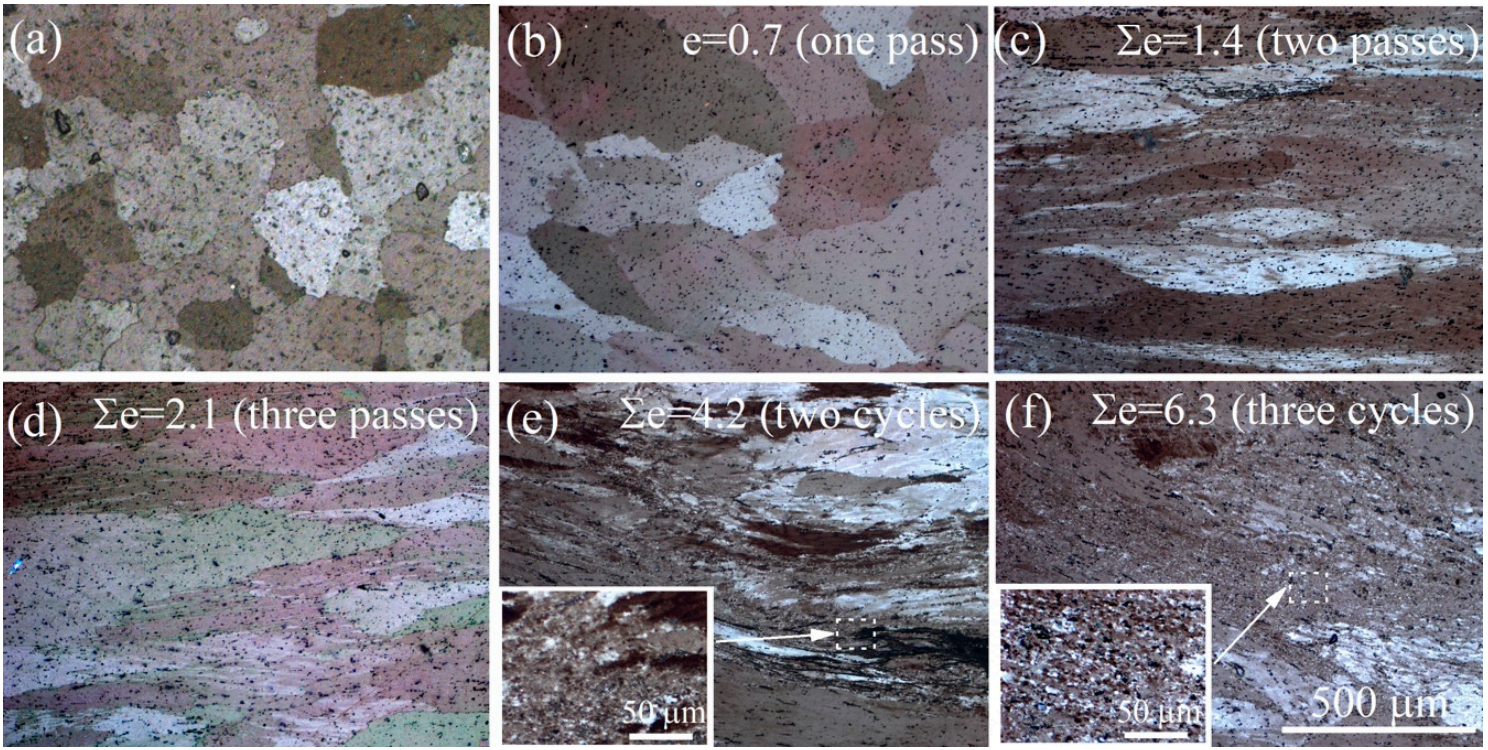

Figure 3. Evolution of the grain structure in the near-surface layer during isothermal multidirectional forging at $350{ }^{\circ} \mathrm{C}$ : (a) as-cast structure; (b) the first pass along the z-axis; (c) the second pass along the $\mathrm{y}$-axis; (d) the third pass along the $\mathrm{x}$-axis; (e) two cycles with $\sum \mathrm{e}=4.2 ;(\mathbf{f})$ three cycles with $\sum \mathrm{e}=6.3$; inserts in the (e) and (f) grain structures of the local places at a higher magnification; polarized light, optical microscope.
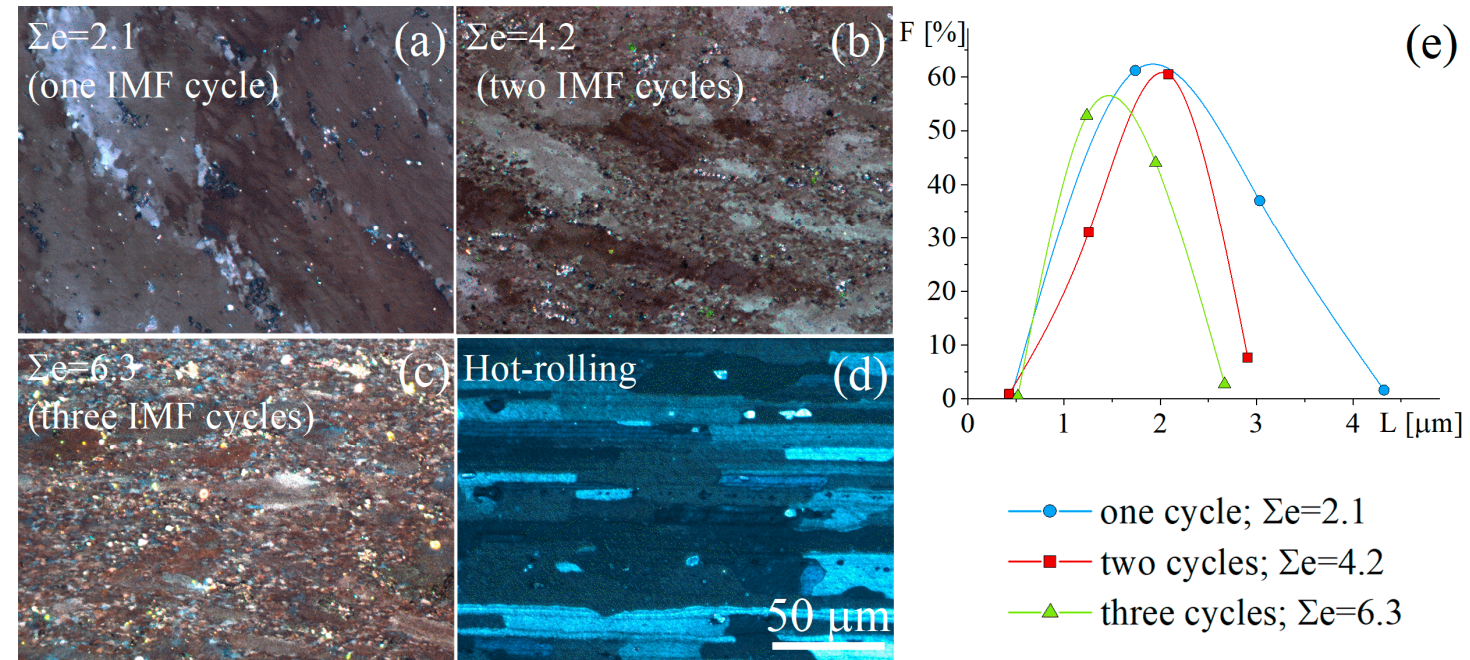

Figure 4. The grain structure in the center part of the sample $(\mathbf{a}-\mathbf{c})$ isothermal multidirectional forging at $350{ }^{\circ} \mathrm{C}$ at various cumulative strains: (a) 2.1 , (b) 4.2 , and (c) 6.3 ; (d) grain structure after hot rolling with a strain of 2.14; polarized light, optical microscope, (e) grain size distribution.

3.2. Grain Structure Evolution of IMF Proceeded Samples at Annealing in a Temperature Range of $450-540{ }^{\circ} \mathrm{C}$ (Mode A)

Samples subjected to the IMF with $\sum \mathrm{e}=6.3$ (mode A) were annealed at 450,500 , and $540{ }^{\circ} \mathrm{C}$ for $30 \mathrm{~min}$. The solidus temperature of an alloy is $560^{\circ} \mathrm{C}$ [41]. The grain structure exhibited bimodality after annealing in a studied temperature range (Figure 5). The grain size distributions in a fine grain area are shown in Figure $5 \mathrm{~h}$. The mean grain size in a fine-grained area increased from $1.2 \pm 0.1$ after 
IMF to $1.9 \pm 0.1,5.0 \pm 0.1$, and $9.4 \pm 0.1 \mu \mathrm{m}$ after annealing at 450,500 , and $540{ }^{\circ} \mathrm{C}$, respectively. Coarse grains varied in a range of $13-150 \mu \mathrm{m}$ at all studied temperatures (Figure 5i).

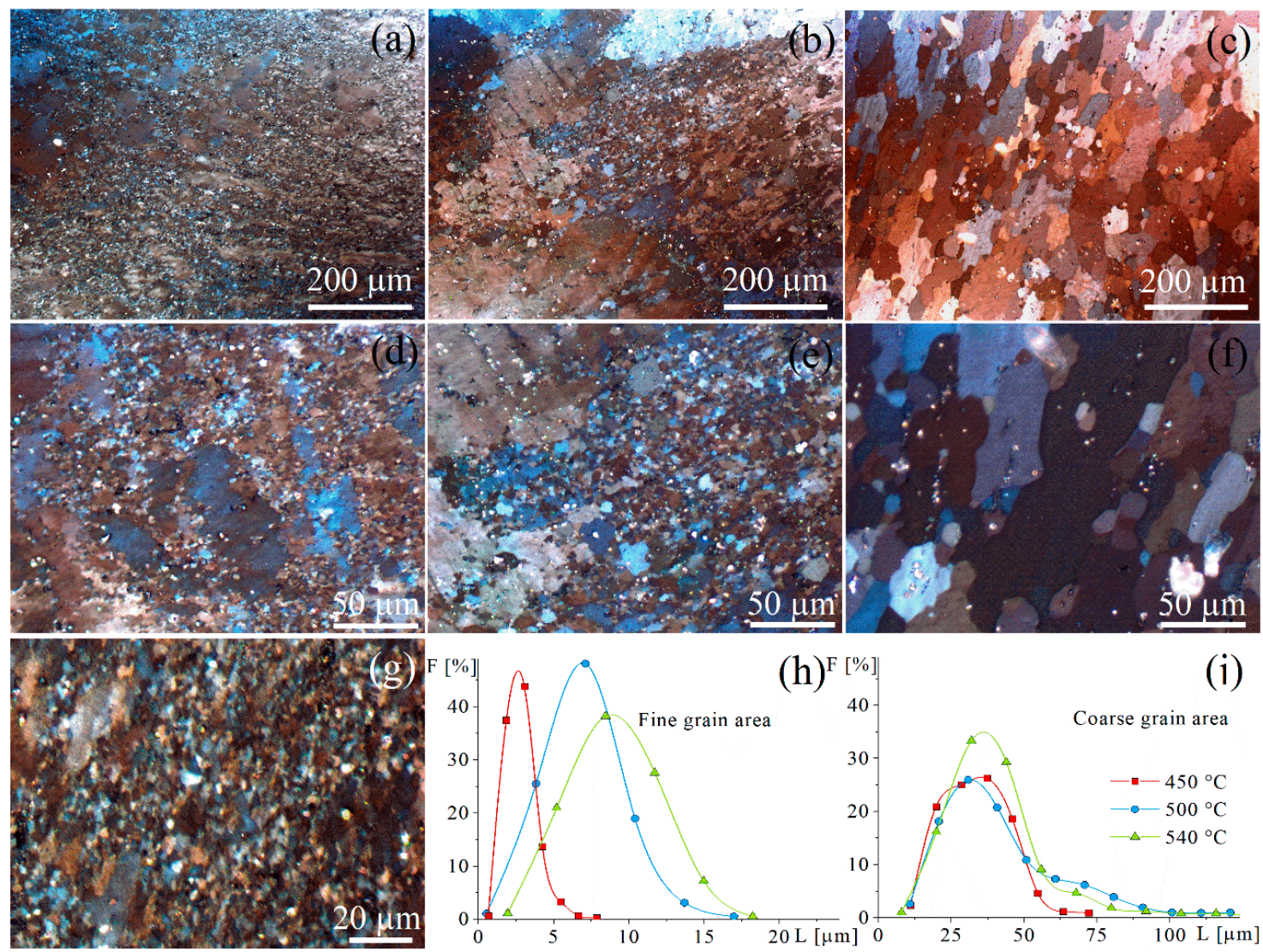

Figure 5. The grain structure in the center part of the sample after isothermal multidirectional forging at $350{ }^{\circ} \mathrm{C}$ with a cumulative strain of 6.3 and subsequent annealing at (a,d,g) 450, (b,e) 500 and (c,f) $540{ }^{\circ} \mathrm{C}$ for $30 \mathrm{~min}$; (h) and (i) the grain size distribution in fine grain and coarse grain areas.

The dynamic recrystallization partially occurred in the places where a critical strain was reached at IMF (Figure 4c). The new grains were formed on the original grain boundaries and in the MS bands. The fraction of recrystallized equiaxed grains insignificantly increased at annealing (Figure 5). Therefore, in most of the non-recrystallized grains, the strain at IMF did not exceed the critical strain value required to start the recrystallization at subsequent annealing. As a result, the grain structure in the IMF processed sample and the sample after IMF and subsequent annealing exhibited significant inhomogeneity. The grain growth was significant especially at the sub-solidus temperature of $540{ }^{\circ} \mathrm{C}$. The mean grain size in the recrystallized volume increased by $\sim 8$ times.

\subsection{Grain Structure of the Sheets (Modes B and C)}

The grain structures of the sample subjected to IMF and cold rolling and the sample subjected to hot and cold rolling (mode C, Figure 1) after recrystallization annealing at $500{ }^{\circ} \mathrm{C}$ (mode B, Figure 1) are presented in Figure 6. The as-annealed samples processed by modes B (Figure 6a) and C (Figure 4b) demonstrated high homogeneity. The grain size distributions are shown in Figure $6 \mathrm{c}$ and the grain parameters are presented in Table 2. The mean grain size was $4.8 \pm 0.1 \mu \mathrm{m}$ in the sample pre-treated by IMF (mode B). The sample exposed to simple thermo-mechanical treatment exhibited less equiaxed grains (mode $C$ ). The mean grain size was $8.0 \pm 0.3 \mu \mathrm{m}$. The grain size varied in a range of 2 to $13 \mu \mathrm{m}$ in mode B and from 2 to $26 \mu \mathrm{m}$ in mode C (Figure 6c). The fraction of fine grains was significantly higher in the sample processed by mode $B$. 

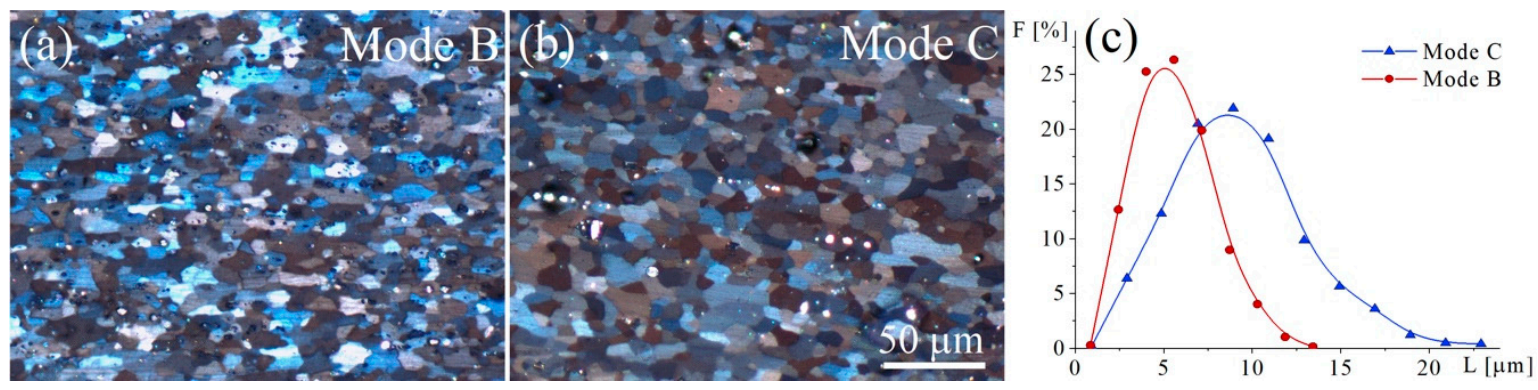

Figure 6. Grain structures after annealing at $500{ }^{\circ} \mathrm{C}$ for $30 \mathrm{~min}$ : (a) mode $\mathrm{B},(\mathbf{b})$ mode $\mathrm{C}$, (c) grain size distributions.

Table 2. Mean grain size after recrystallization annealing of the sheets at $500{ }^{\circ} \mathrm{C}$ for $30 \mathrm{~min}$.

\begin{tabular}{ccc}
\hline Treatment & Mode B & Mode C \\
\hline Mean grain size, $\mu \mathrm{m}$ & $4.8 \pm 0.1$ & $8.0 \pm 0.3$ \\
Form factor & 0.79 & 0.73 \\
\hline
\end{tabular}

\subsection{Tensile Test}

\subsubsection{Superplastic Behavior at Elevated Temperatures}

Figure 7 demonstrates the flow stress vs. strain rate curves $(\mathrm{a}, \mathrm{c})$ and the strain rate sensitivity $m$-index vs. the strain rate $(\mathrm{b}, \mathrm{d})$ at $500{ }^{\circ} \mathrm{C}$ and $540{ }^{\circ} \mathrm{C}$ for the samples processed by modes $\mathrm{A}, \mathrm{B}$ and $\mathrm{C}$.
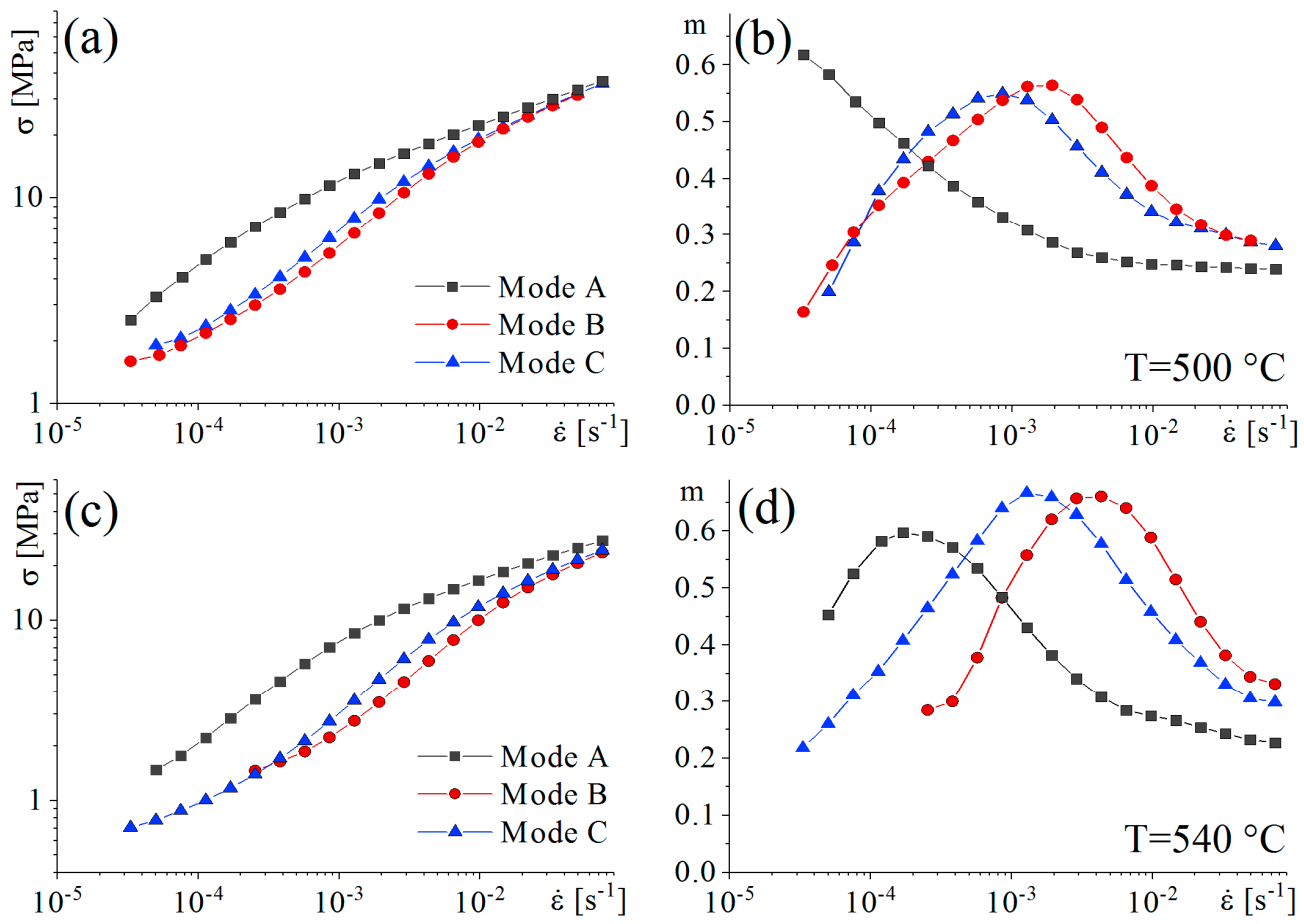

Figure 7. The flow stress $(\mathbf{a}, \mathbf{c})$ and $m$-index $(\mathbf{b}, \mathbf{d})$ vs. the strain rate at $500(\mathbf{a}, \mathbf{b})$ and $540{ }^{\circ} \mathrm{C}(\mathbf{c}, \mathbf{d})$.

For mode B-processed samples, the liner part of the stress-strain rate curves corresponded to the superplastic behavior with $m>0.3$ being observed in a range of $1 \times 10^{-4}$ to $2 \times 10^{-2} \mathrm{~s}^{-1}$ at $500{ }^{\circ} \mathrm{C}$ and in a range of $1 \times 10^{-3}$ to $4 \times 10^{-2} \mathrm{~s}^{-1}$ at $540{ }^{\circ} \mathrm{C}$ (red curves in Figure 7 ). Mode $\mathrm{C}$ provided lower superplastic strain rates and $m$-values (blue curves in Figure 7). The samples exposed to IMF (mode A) exhibited $m>0.3$ at strain rates lower than $2 \times 10^{-3} \mathrm{~s}^{-1}$ (black curves in Figure 7) due to significant grain structure inhomogeneity after IMF. 
Constant strain rate tests were carried out at strain rates of $1 \times 10^{-3}, 5 \times 10^{-3}$ and $1 \times 10^{-2} \mathrm{~s}^{-1}$ (Figure 8). The flow stress was lower at $540{ }^{\circ} \mathrm{C}$ as compared with at $500{ }^{\circ} \mathrm{C}$ for all studied modes and strain rates (Figure $8 \mathrm{a}-\mathrm{c}$ ). The samples exposed to IMF (mode A) demonstrated non-superplastic behavior with necking and an elongation to failure of less than $150 \%$ due to the presence of a non-uniform grain structure after IMF.
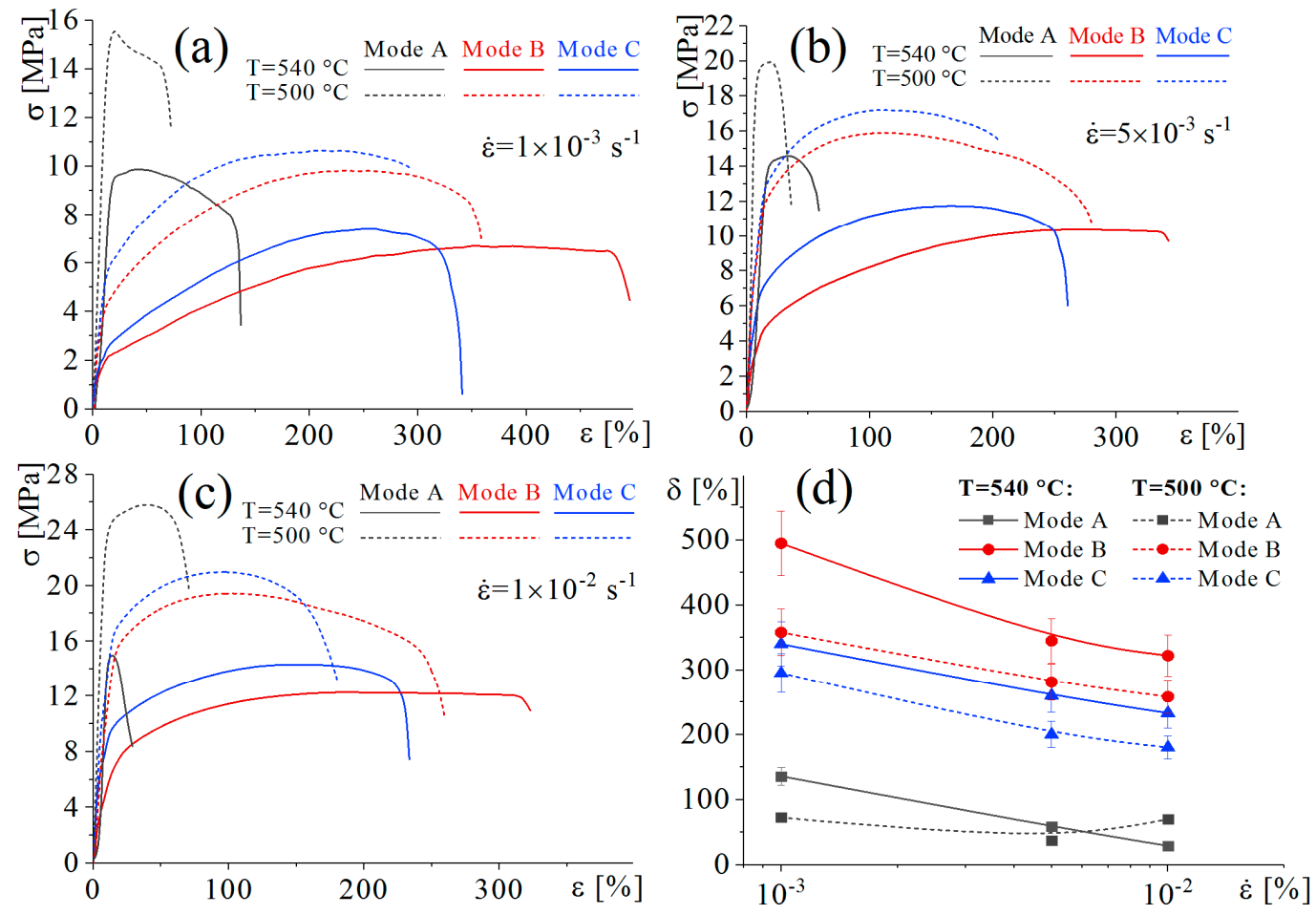

Figure 8. The flow stress-strain curves at constant strain rates of $1 \times 10^{-3} \mathrm{~s}^{-1}(\mathbf{a}), 5 \times 10^{-3} \mathrm{~s}^{-1}(\mathbf{b})$ and $1 \times 10^{-2} \mathrm{~s}^{-1}$ (c) and (d) elongation to failure at temperatures of $500{ }^{\circ} \mathrm{C}$ and $540{ }^{\circ} \mathrm{C}$.

Mode B provided lower stress values and a more stable steady stage as compared with mode $\mathrm{C}$ due to a finer grain structure. A maximum elongation of 500\% and a stress value below $7 \mathrm{MPa}$ were observed in the samples processed by IMF and cold rolling (Mode B) at $540{ }^{\circ} \mathrm{C}$ and $1 \times 10^{-3} \mathrm{~s}^{-1}$. This mode provided high strain rate superplasticity in the studied conventional alloy. At $540{ }^{\circ} \mathrm{C}$ and $1 \times 10^{-2} \mathrm{~s}^{-1}$, the mean elongation to failure exceeded $340 \%$ (Figure $8 \mathrm{~d}$ ) and $m=0.6$ (Figure $7 \mathrm{~b}$ ).

\subsubsection{Room Temperature Tensile Tests}

The room temperature mechanical properties of the samples exposed to modes $\mathrm{A}, \mathrm{B}$, and $\mathrm{C}$ and the as-annealed samples are presented in Table 3.

Table 3. Mechanical properties at room temperature.

\begin{tabular}{cccc}
\hline Mode & Yield Strength, MPa & Ultimate Tensile Strength, MPa & $\boldsymbol{\delta}, \boldsymbol{\%}$ \\
\hline Mode A & $300 \pm 5$ & $405 \pm 4$ & $17 \pm 1$ \\
Mode B, as-rolled & $500 \pm 5$ & $525 \pm 7$ & $3 \pm 1$ \\
Mode B, annealing at 500 ${ }^{\circ} \mathrm{C}$ for 30 min & $195 \pm 3$ & $335 \pm 5$ & $27 \pm 2$ \\
Mode C, as-rolled & $235 \pm 5$ & $475 \pm 6$ & $10 \pm 1$ \\
Mode C, annealing at 500 ${ }^{\circ} \mathrm{C}$ for 30 min & $175 \pm 5$ & $320 \pm 5$ & $21 \pm 1$ \\
\hline
\end{tabular}

IMF provided a YS of $300 \mathrm{MPa}$ and a UTS of $405 \mathrm{MPa}$. However, a typical YS value is 170-180 MPa and a typical UTS value is 300-320 MPa for conventionally proceeded samples [44], and mode C-processed samples exhibited similar values. Despite the inhomogeneous grain structure, samples 
exposed to IMF exhibited $17 \%$ elongation, which is close to the values of conventionally processed sheets. The increased strength is explained by the presence of an ultrafine grain structure with $~ 50 \%$ of fine grains being $1.2-2.9 \mu \mathrm{m}$ in size. The rolling at room temperature increased the YS to $500 \mathrm{MPa}$, which is higher than that of many high strength Al-based alloys of the AA7000 series after solid solution treatment and peak aging. The cold-rolled samples processed by IMF-free Mode $\mathrm{C}$ exhibited a YS of $235 \mathrm{MPa}$ and a UTS of $475 \mathrm{MPa}$ and 10\% elongation. The significant increase in YS and the decrease in room temperature elongation were observed, due to the inclusion of the IMF treatment in the sheet processing. The elevated temperature annealing at $500{ }^{\circ} \mathrm{C}$ for mode B-processed samples provided slightly higher strength characteristics (YS = $195 \mathrm{MPa}$ and UTS $=335 \mathrm{MPa}$ ) and significantly higher elongation at room temperature $(27 \%)$ compare to simple treatment by Mode C.

In summary, samples exposed to IMF exhibited increased strength, due to their high fraction of ultrafine grains, and failed superplasticity, due to their grain structure inhomogeneity. Further increasing the cumulative strain at MDF should increase grain structure homogeneity and should improve the superplastic and mechanical properties. Despite the fact that increasing the number of passes makes the production process more expensive and complex, further investigations on the microstructure and properties of light aluminum alloys exposed to multi-axial deformation are important, and those materials are promising for various industrial applications. Applying the IMF as an intermediate operation in the sheet processing helped to form fine homogeneous grain structures after cold rolling and subsequent recrystallization annealing. As a result, samples exposed to treatment with IMF exhibited increased strength at room temperature and high strain rate superplasticity at elevated temperatures.

\section{Conclusions}

The grain structure evolution, mechanical properties and superplastic behavior of the samples of an Al-Mg-Mn-based alloy subjected to isothermal multidirectional forging (IMF) at $350{ }^{\circ} \mathrm{C}$ with a cumulative strain of 1.4 to 6.3 and a strain per pass of 0.7 were analyzed. Microstructure and properties of Samples exposed to IMF with subsequent cold rolling, and samples after simple hot and cold rolling were compared. The conclusions are summarized as follows:

(1) The micro-shear bands were formed inside the original grains after the second $\left(\sum \mathrm{e}=1.4\right)$ and the third $\left(\sum \mathrm{e}=2.1\right)$ IMF passes, and the dynamic recrystallization started during the third IMF pass. The fraction of recrystallized grains increased, and their size decreased in both the periphery and central part of the sample as the cumulative strain increased from 2.1 to 6.3.

(2) The IMF processed samples exhibited a non-homogeneous grain structure consisting of fine and coarse grain areas. The sizes of original coarse grains varied in a range of 30-140 $\mu \mathrm{m}$. Fifty-seven percent of recrystallized grains with a mean size of $1.2 \mu \mathrm{m}$ were observed in the central part and $43 \%$ of recrystallized grains with a mean size of $2.9 \mu \mathrm{m}$ were observed in the periphery of the samples. The recrystallized fraction was unchanged, and the grain growth occurred in the fine-grained area during annealing in a temperature range of $450-540{ }^{\circ} \mathrm{C}$, leading to an increase in the mean grain size of 1.9-9.4 $\mu \mathrm{m}$. The IMF processed samples exhibited an ultimate tensile strength (UTS) of $405 \mathrm{MPa}$, a yield strength (YS) of $300 \mathrm{MPa}$ and an elongation to failure of $17 \%$. The non-homogeneous grain structure resulted in non-superplastic behavior of the alloy in a strain rate range of $10^{-3}$ to $10^{-2} \mathrm{~s}^{-1}$ at 500 and $540^{\circ} \mathrm{C}$.

(3) The sheets exposed to IMF with subsequent cold rolling and recrystallization annealing at $500{ }^{\circ} \mathrm{C}$ demonstrated a homogeneous fine grain structure with a mean size of $4.8 \mu \mathrm{m}$ and high strain rate superplasticity with elongation of 350-500\%, a strain rate sensitivity index of $m=0.5-0.6$ in a strain rate range of $10^{-3}$ to $10^{-2} \mathrm{~s}^{-1}$ at 500 and $540{ }^{\circ} \mathrm{C}$. In comparison, the elongation to failure was $250-350 \%$, and the mean grain size was $8.0 \mu \mathrm{m}$ in the sheets processed by simple thermo-mechanical treatment. Cold rolling of IMF-processed samples led to an increase in YS to $500 \mathrm{MPa}$ : two times higher than that of samples subjected to a simple thermo-mechanical treatment which included hot and cold rolling. 
Author Contributions: Conceptualization, A.V.M. and V.K.P.; Methodology, M.S.K., A.S.P. and A.D.K.; Validation, A.D.K. Investigation, M.S.K., A.S.P. and A.D.K.; Resources, M.S.K. and V.K.P. Data Curation, A.D.K.; Writing-Original Draft Preparation, A.V.M. and A.D.K. and; Writing-Review \& Editing A.V.M.; Visualization, A.D.K.; Supervision, A.V.M. and V.K.P.

Funding: The work was funded within the RFFI Grant \#18-03-01115.

Conflicts of Interest: The authors declare no conflict of interest. The founding sponsors had no role in the design of the study; in the collection, analysis, or interpretation of data; in the writing of the manuscript, or in the decision to publish the results.

\section{References}

1. Langdon, T.G. Twenty-five years of ultrafine-grained materials: Achieving exceptional properties through grain refinement. Acta Mater. 2013, 61, 7035-7059. [CrossRef]

2. Sabirov, I.; Murashkin, M.; Yu, R.Z. Valiev, Nanostructured aluminium alloys produced by severe plastic deformation: New horizons in development. Mater. Sci. Eng. A 2013, 560, 1-24. [CrossRef]

3. Kawasaki, M.; Ahn, B.; Kumar, P.; Jang, J.; Langdon, T.G. Nano- and Micro-Mechanical Properties of Ultrafine-Grained Materials Processed by Severe Plastic Deformation Techniques. Adv. Eng. Mater. 2017, 19, 1-17. [CrossRef]

4. Estrin, Y.; Vinogradov, A. Extreme grain refinement by severe plastic deformation: A wealth of challenging science. Acta Mater. 2013, 61, 782-817. [CrossRef]

5. Valiev, R.Z.; Sabirov, I.; Zhilyaev, A.P.; Langdon, T.G. Bulk nanostructured metals for innovative applications. JOM 2012, 64, 1134-1142. [CrossRef]

6. Zhilyaev, A.P.; Langdon, T.G. Using high-pressure torsion for metal processing: Fundamentals and applications. Prog. Mater. Sci. 2008, 53, 893-979. [CrossRef]

7. Sakai, T.; Belyakov, A.; Kaibyshev, R.; Miura, H.; Jonas, J.J. Dynamic and post-dynamic recrystallization under hot, cold and severe plastic deformation conditions. Prog. Mater. Sci. 2014, 60, 130-207. [CrossRef]

8. Cao, Y.; Ni, S.; Liao, X.; Song, M.; Zhu, Y. Structural evolutions of metallic materials processed by severe plastic deformation. Mater. Sci. Eng. R Rep. 2018, 133, 1-59. [CrossRef]

9. Sitdikov, O.; Sakai, T.; Goloborodko, A.; Miura, H.; Kaibyshev, R. Effect of pass strain on grain refinement in $7475 \mathrm{Al}$ alloy during hot multidirectional forging. Mater. Trans. 2004, 45, 2232-2238. [CrossRef]

10. Estrin, Y.; Murashkin, M.; Valiev, R. Ultrafine-Grained Aluminium Alloys: Processes, Structural Features and Properties. Fundamentals of Aluminium Metallurgy: Production, Processing and Applications; Publisher Woodhead Publishing: Great Britain, UK, 2011; pp. 468-503.

11. Mogucheva, A.; Yuzbekova, D.; Kaibyshev, R. Superplasticity in a 5024 aluminium alloy subjected to ECAP and subsequent cold rolling. Mater. Sci. Forum 2016, 838-839, 428-433. [CrossRef]

12. Avtokratova, E.V.; Sitdikov, O.S.; Markushev, M.V. Superplasticity of Al-Mg-Sc(Zr) alloys, subjected to intense plastic deformation(Review). Mater. Phys. Mech. 2017, 33, 19-28.

13. Valiev, R.Z.; Salishchev, G.A.; Utyashev, F.Z.; Langdon, T.G. Studies on the superplasticity effect in UFA: History and development. Rev. Adv. Mater. Sci. 2018, 54, 14-24.

14. Valiev, R.Z.; Salimonenko, D.A.; Tsenev, N.K.; Berbon, P.B.; Langdon, T.G. Observations of high strain rate superplasticity in commercial aluminum alloys with ultrafine grain sizes. Scr. Mater. 1997, 37, 1945-1950. [CrossRef]

15. Kawasaki, M.; Langdon, T.G. Principles of superplasticity in ultrafine-grained materials. Rev. Adv. Mater. Sci. 2018, 54, 46-55. [CrossRef]

16. Markushev, M.V. On the methods of severe plastic deformation for bulk nanomaterials processing. Lett. Mater. 2011, 1, 36-42. [CrossRef]

17. Mulyukov, R.R.; Imayev, R.M.; Nazarov, A.A. Production, properties and application prospects of bulk nanostructured materials. J. Mater. Sci. 2008, 43, 7257-7263. [CrossRef]

18. Bereczki, P.; Szombathely, V.; Krallics, G. Production of ultrafine grained aluminum by cyclic severe plastic deformation at ambient temperature. IOP Conf. Ser. Mater. Sci. Eng. 2014, 63, 012140. [CrossRef]

19. Rao, P.N.; Singh, D.; Jayaganthan, R. Mechanical properties and microstructural evolution of Al 6061 alloy processed by multidirectional forging at liquid nitrogen temperature. Mater. Des. 2014, 56, 97-104. [CrossRef] 
20. Sitdikov, O.; Garipova, R.; Avtokratova, E.; Mukhametdinova, O.; Markushev, M. Effect of temperature of isothermal multidirectional forging on microstructure development in the Al-Mg alloy with nano-size aluminides of Sc and Zr. J. Alloys Compd. 2018, 746, 520-531. [CrossRef]

21. Jandaghi, M.R.; Pouraliakbar, H.; Gharah Shiran, M.K.; Khalajd, G.; Shirazie, M. On the effect of non-isothermal annealing and multi-directional forging on the microstructural evolutions and correlated mechanical and electrical characteristics of hot-deformed Al-Mg alloy. Mater. Sci. Eng. A 2016, 657, 431-440. [CrossRef]

22. Armstrong, P.E.; Hockett, J.E.; Sherby, O.D. Large Deformation of 1100 Aluminum at 300 K. J. Mech. Phys. Solids 1982, 30, 37-58. [CrossRef]

23. Xu, X.; Zhang, Q.; Hu, N.; Huang, Y.; Langdon, T.G. Using an Al-Cu binary alloy to compare processing by multi-axial compression and high-pressure torsion. Mater. Sci. Eng. A 2013, 588, 280-287. [CrossRef]

24. Buckingham, R.C.; Argyrakis, C.; Hardy, M.C.; Birosca, S. The effect of strain distribution on microstructural developments during forging in a newly developed nickel base superalloy. Mater. Sci. Eng. A 2016, 654, 317-328. [CrossRef]

25. Montazeri-Pour, M.; Parsa, M.H.; Jafarian, H.R.; Taieban, S. Microstructural and mechanical properties of AA1100 aluminum processed by multi-axial incremental forging and shearing. Mater. Sci. Eng. A 2015, 639, 705-716. [CrossRef]

26. Zhu, Q.; Li, L.; Ban, C.; Zhao, Z.; Zuo, Y.; Cui, J. Structure uniformity and limits of grain refinement of high purity aluminum during multi-directional forging process at room temperature. Trans. Nonferrous Met. Soc. China 2014, 24, 1301-1306. [CrossRef]

27. Snopiński, P.; Król, M. Microstructure, Mechanical Properties and Strengthening Mechanism Analysis in an AlMg5 Aluminium Alloy Processed by ECAP and Subsequent Ageing. Metals 2018, 8, 969. [CrossRef]

28. Khani Moghanaki, S.; Kazeminezhad, M.; Logé, R. Mechanical behavior and texture development of over-aged and solution treated Al-Cu-Mg alloy during multi-directional forging. Mater. Charact. 2018, 135, 221-227. [CrossRef]

29. Dashti, A.; Shaeri, M.; Taghiabadi, R.; Djavanroodi, F.; Vali Ghazvini, F.; Javadi, H. Microstructure, Texture, Electrical and Mechanical Properties of AA-6063 Processed by Multi Directional Forging. Materials 2018, 11, 2419. [CrossRef]

30. Sitdikov, O.; Sakai, T.; Goloborodko, A.; Miura, H.; Kaibyshev, R. Grain refinement in coarse-grained $7475 \mathrm{Al}$ alloy during severe hot forging. Philos. Mag. 2005, 85, 1159-1175. [CrossRef]

31. Sitdikov, O.; Sakai, T.; Miura, H.; Hama, C. Temperature effect on fine-grained structure formation in high-strength $\mathrm{Al}$ alloy 7475 during hot severe deformation. Mater. Sci. Eng. A 2009, 516, 180-188. [CrossRef]

32. Wang, M.; Huang, L.; Liu, W.; Ma, Y.; Huang, B. Influence of cumulative strain on microstructure and mechanical properties of multi-directional forged 2A14 aluminum alloy. Mater. Sci. Eng. A 2016, 674, 40-51. [CrossRef]

33. Aoba, T.; Kobayashi, M.; Miura, H. Microstructural evolution and enhanced mechanical properties by multi-directional forging and aging of 6000 series aluminum alloy. Mater. Trans. 2018, 59, 373-379. [CrossRef]

34. Noda, M.; Hirohashi, M.; Funami, K. Low temperature superplasticity and its deformation mechanism in grain refinement of Al-Mg alloy by multi-axial alternative forging. Nippon Kinzoku Gakkaishi/J. Jpn. Inst. Met. 2003, 67, 98-105. [CrossRef]

35. Ben Naser, T.S.; Krallics, G. The Superplasticity Behavior of Multiple Forged Al7075 Alloy. Int. J. Innov. Res. Adv. Eng. 2016, 2, 61-65.

36. Cao, F.; Xue, G.; Xu, G. Superplasticity of a dual-phase-dominated Mg-Li-Al-Zn-Sr alloy processed by multidirectional forging and rolling. Mater. Sci. Eng. A 2017, 704, 360-374. [CrossRef]

37. Li, J.L.; Wu, D.; Yang, Q.B.; Chen, R.S. Superplasticity of multi-directional impact forged Mg-Gd-Y-Zr alloy. J. Alloy. Compd. 2016, 672, 27-35. [CrossRef]

38. Xing, J.; Yang, X.; Miura, H.; Sakai, T. Superplasticity of Fine-Grained Magnesium Alloy AZ31 Processed by Multi-Directional Forging. Mater. Trans. 2007, 48, 1406-1411. [CrossRef]

39. Zhang, Z.-R.; Xing, J.; Yang, X.; Miura, H.; Sakai, T. Anisotropy of low temperature superplasticity of fine grained magnesium alloy AZ31 processed by multidirectional forging. Mater. Sci. Technol. 2009, 25, 1442-1447. [CrossRef]

40. Xing, J.; Yang, X.Y.; Miura, H.; Sakai, T. Low Temperature Superplasticity of Fine-Grained Magnesium Alloy AZ31. Adv. Mater. Res. 2007, 15-17, 467-472. [CrossRef] 
41. Kishchik, M.S.; Mikhailovskaya, A.V.; Levchenko, V.S.; Kotov, A.D.; Drits, A.M.; Portnoy, V.K. Formation of Fine-Grained Structure and Superplasticity in Commercial Aluminum Alloy 1565ch. Met. Sci. Heat Treat. 2017, 58, 543-547. [CrossRef]

42. Faraji, G.; Kim, H.S.; Kashi, H.T. Severe Plastic Deformation: Methods, Processing and Properties; Elsevier: Amsterdam, The Netherlands, 2018; p. 324. ISBN 9780128135679.

43. Sakai, T.; Jonas, J.J. Plastic deformation: Role of recovery and recrystallization. Encycl. Mater. Sci. Technol. 2001, 7, 7079.

44. Kishchik, M.S.; Mikhaylovskaya, A.V.; Kotov, A.D.; Mosleh, A.O.; AbuShanab, W.S.; Portnoy, V.K. Effect of multidirectional forging on the grain structure and mechanical properties of the Al-Mg-Mn alloy. Materials 2018, 11, 2166. [CrossRef] [PubMed]

(C) 2019 by the authors. Licensee MDPI, Basel, Switzerland. This article is an open access article distributed under the terms and conditions of the Creative Commons Attribution (CC BY) license (http:/ / creativecommons.org/licenses/by/4.0/). 